\title{
Incidência de Anaplasma marginale, Babesia bigemina e Babesia bovis em bezerros no semiárido paraibano ${ }^{1}$
}

\author{
Valéria M.M. Costa르, Múcio Flávio B. Ribeiro³ ${ }^{3}$ Giuliana A.F.P. Duarte ${ }^{4}$, \\ João Fábio Soares ${ }^{5}$, Sergio S. Azevedo ${ }^{4}$, Antonio Thadeu M. Barros ${ }^{6}$, \\ Franklin Riet-Correa ${ }^{4}$ e Marcelo B. Labruna ${ }^{7 *}$
}

\begin{abstract}
Costa V.M.M., Ribeiro M.F.B., Duarte G.A.F.P., Soares J.F., Azevedo S.S., Barros A.T.M., Riet-Correa F. \& Labruna M.B. 2018. [Incidence of Anaplasma marginale, Babesia bigemina and Babesia bovis among calves in the semiarid region of Paraiba, Brazil.] Incidência de Anaplasma marginale, Babesia bigemina e Babesia bovis em bezerros no semiárido paraibano. Pesquisa Veterinária Brasileira 38(4):605-612. Departamento de Medicina Veterinária Preventiva e Saúde Animal, Universidade de São Paulo, Avenida Prof. Orlando Marques de Paiva 87, São Paulo, SP 05508-270, Brazil. E-mail: labruna@usp.br

This study evaluated the incidence of natural infection by agents of cattle tick fever (CTF), Anaplasma marginale, Babesia bovis and Babesia bigemina in calves born in five farms within the semiarid region of Paraíba state, Brazil. In each farm, blood samples were collected from 6 to 14 calves every 14 days during the first 12 months of life of each animal. Blood samples were processed by microhematocrit and tested by PCR for detection of DNA of A. marginale, $B$. bovis and B. bigemina. In parallel, the tick infestations on animals were quantified in the five farms, as well as populations in horseflies in three farms. From a total of 41 calves monitored during the first year of life, $25(61.0 \%)$ had positive PCR for A. marginale, 7 (17.1\%) for B. bigemina and $3(7.3 \%)$ to $B$. bovis. Incidence values for $A$. marginale infection ranged from $83.3 \%$ to $100 \%$ in four farms. Infection with B. bigemina in calves was detected at only two farms (incidence of $12.5 \%$ and $85.7 \%$ ) and by B. bovis in just one (42.8\% incidence). On one farm 14 calves remained negative for $A$. marginale, B. bigemina and B. bovis during the 12 month follow-up. PCR results were confirmed by DNA sequencing of amplified products. The presence of Rhipicephalus (Boophilus) microplus was found only in two farms in which there was infection by A. marginale, B. bigemina and B. bovis (the latter agent in only one of them). A total of 930 horseflies were captured in the study, most during periods of rain in the region; $70.7 \%$ of horseflies corresponded to Tabanus claripennis. There was significant association between a positive PCR for A. marginale and B. bigemina and lower hematocrit values. This study demonstrates that even evaluating only five rural properties, the incidence of CTF occurred heterogeneously in the region, confirming the status of enzootic instability area for CTF, previously reported for the semiarid region of Paraiba.
\end{abstract}

INDEX TERMS: Anaplasma marginale, Babesia bigemina, Babesia bovis, calves, cattle, cattle tick fever, ticks, hematophagous Diptera, Brazil, parasitoses.

\footnotetext{
${ }^{1}$ Recebido em 29 de maio de 2016.

Aceito para publicação em 7 de abril de 2017

${ }^{2}$ Vet Análises, Laboratório de Diagnósticos Veterinário, Rua Coronel José Vicente 68, $1^{\circ}$ andar, Centro, Sousa, PB 58800-005, Brasil.

${ }^{3}$ Departamento de Parasitologia, Instituto de Ciências Biológicas, Universidade Federal de Minas Gerais, Av. Antônio Carlos 6627, Pampulha, Cx. Postal 486, Belo Horizonte, MG 31270-901, Brasil.

${ }^{4}$ Unidade Acadêmica de Medicina Veterinária, Centro de Saúde e Tecnologia Rural da Universidade Federal de Campina Grande, Av. Universitária s/n, Santa Cecília, Cx. Postal 61, Patos, PB 58700-970, Brasil.
}

\footnotetext{
${ }^{5}$ Departamento de Patologia e Clínica Veterinária, Faculdade de Veterinária, Universidade Federal do Rio Grande do Sul, Av. Bento Gonçalves 9090, Porto Alegre, RS 91540000, Brasil.

${ }^{6}$ Embrapa Gado de Corte, Av. Rádio Maia 830, Vila Popular, Campo Grande, MS 79106550, Brasil.

${ }^{7}$ Departamento de Medicina Veterinária Preventiva e Saúde Animal, Faculdade de Medicina Veterinária e Zootecnia, Universidade de São Paulo, Avenida Prof. Orlando Marques de Paiva 87, São Paulo, SP 05508-270, Brasil. *Autor para correspondência: labruna@usp.br
} 
RESUMO.- Este estudo avaliou a incidência de infecções naturais pelos agentes da tristeza parasitária bovina (TPB), Anaplasma marginale, Babesia bovis e Babesia bigemina, em bezerros nascidos em cinco fazendas do semiárido paraibano. Em cada fazenda, foram coletadas amostras de sangue de 6 a 14 bezerros a cada 14 dias durante os primeiros 12 meses de vida de cada animal. As amostras de sangue foram processadas por microhematócrito e testadas por PCR para detecção de DNA de A. marginale, B. bovis e B. bigemina. Em paralelo, foram quantificadas as infestações por carrapatos nos bovinos nas cinco fazendas, assim como as populações de tabanídeos em três fazendas. De 41 bezerros monitorados durante o primeiro ano de vida, $25(61,0 \%)$ apresentaram PCR positivo para A. marginale, $7(17,1 \%)$ para B. bigemina e $3(7,3 \%)$ para $B$. bovis. Os valores de incidência da infecção por $A$. marginale variaram de $83,3 \%$ a $100 \%$ em quatro fazendas. A infecção por B. bigemina ocorreu em bezerros de apenas duas fazendas (incidências de 12,5\% e 85,7\%) e a por B. bovis em apenas uma (incidência de $42,8 \%$ ). Em uma fazenda os 14 bezerros permaneceram negativos para A. marginale, B. bigemina e B. bovis durante os 12 meses de acompanhamento. Os resultados de PCR foram confirmados por sequenciamento de DNA de produtos amplificados. A presença de carrapatos Rhipicephalus (Boophilus) microplus foi verificada somente em duas propriedades, nas quais houve infecção por A. marginale, B. bigemina e B. bovis (este último agente em apenas uma delas). Foram capturados 930 tabanídeos no estudo, a maioria durante os períodos de chuvas na região; $70,7 \%$ dos tabanídeos corresponderam a Tabanus claripennis. Houve associação significativa entre PCR positivo para A. marginale ou B. bigemina e menores valores de hematócrito. Este estudo demonstra que, mesmo avaliando apenas cinco propriedades rurais, a incidência dos agentes da TPB ocorreu de forma heterogênea na região, corroborando o status de área de instabilidade enzoótica para TPB previamente relatado para o semiárido paraibano.

TERMOS DE INDEXAÇÃO: Anaplasma marginale, Babesia bigemina, Babesia bovis, bezerro, bovinos, Paraíba, tristeza parasitária bovina, carrapatos, dípteros hematófagos, parasitoses.

\section{INTRODUÇÃO}

A tristeza parasitária bovina (TPB) é considerada enzoótica no Brasil e a distribuição geográfica de seus agentes etiológicos, Anaplasma marginale, Babesia bigemina e Babesia bovis, está relacionada principalmente com a presença do carrapato vetor, Rhipicephalus microplus. Levantamentos soro-epidemiológicos realizados em diferentes regiões do Brasil têm demonstrado ocorrência de variações na frequência de bovinos infectados por estes agentes, estabelecendo áreas de estabilidade enzoótica e áreas de instabilidade (Sacco 2002, Trindade 2010, Souza 2011, Costa et al. 2013, Silva et al. 2015).

As áreas de estabilidade enzoótica são definidas onde existe equilíbrio entre imunidade e doença, onde normalmente mais de 75\% dos animais com idade acima de nove meses são portadores de hemoparasitos. Nestas áreas a maioria dos animais adquire a infecção antes de nove meses de idade e devido à resistência natural à infecção permanecem assintomáticos. Os animais posteriormente são reinfectados continuamente através de novas infestações por $R$. (B.) microplus, se mantendo no estado de portador durante a vida. Esta situação resulta em baixa mortalidade pelas hemoparasitoses em animais adultos (Guglielmone 1995, Sacco 2002, Silva et al. 2015). Em áreas endêmicas, os bezerros apresentam a resistência natural por receberem proteção passiva de anticorpos presentes no colostro até cerca de três meses de idade além da imunidade inata (James et al. 1985, Brown et al. 2006). De forma semelhante, após a primo-infecção, os animais permanecem sorologicamente positivos por um período de seis meses para $B$. bovis, de três a quatro meses para a B. bigemina (Wright 1990) e de oito meses para A. marginale (Magonigle \& Newby 1984).

Em áreas de instabilidade enzoótica, a prevalência de infecção pelos agentes da TPB em animais acima de nove meses está geralmente entre 20 e 75\% (Mahoney \& Ross 1972). Nessas áreas, fatores climáticos ou de manejo interferem no desenvolvimento da fase de vida livre do carrapato. Nesses rebanhos, a primo-infecção é verificada em idade avançada e se caracteriza pela ocorrência de surtos da doença em animais adultos e, consequentemente, altas taxas de mortalidade (Mahoney \& Ross 1972).

0 presente estudo teve como objetivo determinar a incidência de infecções naturais por A. marginale, $B$. bovis e B. bigemina em bezerros a partir dos 30 dias de idade, nascidos em fazendas do semiárido paraibano, onde estudos recentes indicaram se tratar de uma região com características de instabilidade enzoótica para TPB (Costa et al. 2011, 2013).

\section{MATERIAL E MÉTODOS}

O estudo foi desenvolvido na região semiárida de Cariri e Sertão paraibano, pertencente ao bioma Caatinga. Neste bioma o clima semiárido se caracteriza por uma temperatura média de $27^{\circ} \mathrm{C}$ e a precipitação média anual é tipicamente $\approx 500 \mathrm{~mm}$. Ocorrência de secas, por vezes com duração de mais de um ano, também é uma característica da região (Andrade-Lima 1981). A maioria das propriedades criam os bovinos em regime extensivo sobre Caatinga nativa.

Foram selecionadas cinco propriedades rurais, sendo quatro na mesorregião do Sertão (São José de Espinharas (A), Patos (C), Piancó (B e E) e uma na mesorregião do Cariri Paraibano (Cabaceiras (D). Com exceção da propriedade A, todas as demais apresentavam histórico de surtos de TPB nos 5 anos anteriores ao início deste estudo; tais surtos foram reportados anonimamente nos trabalhos de Costa et al. (2011, 2013). Em cada propriedade foram coletadas amostras de sangue de 6 a 14 bezerros a partir dos 30 dias de vida. Posteriormente, foram coletas amostras sanguíneas dos mesmos bezerros a cada 14 dias por um período de 12 meses, dentro do período de julho/2010 a janeiro/2012. As amostras de sangue foram colhidas em tubos com anticoagulante (EDTA), sendo uma parte usada para determinação do volume globular pelo teste de microhematócrito e outra para extração de DNA.

Extração de DNA e testes moleculares. Para a extração de DNA de sangue total, utilizou-se o kit comercial Wizard ${ }^{\circledR}$ Genomic DNA Purification Kit (PROMEGA), conforme recomendações do fabricante, com padronização do volume da amostra para extração de $150 \mu \mathrm{L}$ de sangue total. Três protocolos de PCR, cada um com par de primers espécie-específico, foram empregados para cada espécie de hemoparasita. Os primers utilizados na reação de amplificação para Anaplasma marginale foram: senso (5'-CAA TCG TGA GGG ATA GCC TTG TAC-3') e antisenso (5'-TGG TAT CAC GGT CAA AAT CTT TGC T-3'), que amplificam um fragmento de 300-bp do gene msp1a de A. marginale. Para Babesia bovis cada amostra de DNA foi testada 
com os primers senso (5'-CGA GGA AGG AAC TAC CGA TGT TGA ATA TC-3') e antisenso (5'-CAA CGT ACG AGG TCA AGC TAC CGA GCA G-3'), que amplificam um fragmento de 347-bp do gene rap-1 de B. bovis; e na PCR para Babesia bigemina, cada amostra de DNA foi testada com os primers senso (5'-GGG ACG TCA AGC GAT TTT GAG ACG T-3') e antisenso (5'-GAG TGT TGC TGA TTG ACG ACC TAA GCG C-3'), que amplificam um fragmento de 340-bp do gene rap-1 de B. bigemina. Todas as reações foram realizadas nas mesmas condições de reagentes e ciclos térmicos. Para tal, cada tubo de reação consistiu num volume total final de $25 \mu \mathrm{L}$, com uma mistura contendo $12,6 \mu \mathrm{L}$ de água ultrapura, $2,5 \mu \mathrm{L}$ de tampão a $10 \mathrm{X}, 2,5 \mu \mathrm{L}$ de amostra de DNA de sangue total, $4,0 \mu \mathrm{L}$ de dNTPs a $2 \mathrm{mM}, 0,75 \mu \mathrm{L}$ de $\mathrm{MgCl}_{2}$ a $25 \mathrm{mM}$, $1,25 \mu \mathrm{L}$ de cada primer a $10 \mathrm{mM}$ e $0,15 \mu \mathrm{L}$ de enzima Taq-polimerase a $5 \mathrm{U} / \mu \mathrm{L}$ (Taq-Platinum, Invitrogen). As condições térmicas foram $95^{\circ} \mathrm{C}$ por 3 min., seguido de 40 ciclos de $95^{\circ} \mathrm{C}$ por $15 \mathrm{seg}$., $58^{\circ} \mathrm{C}$ por 30 seg., $72^{\circ} \mathrm{C}$ por 30 seg.; finalmente, houve uma extensão final a $72^{\circ} \mathrm{C}$ por $5 \mathrm{~min}$. Esses três pares de primers foram desenhados durante o presente estudo, utilizando-se o programa Primer Express Software Version 3.0 (Applied Biosystems), porém já foram empregados com sucesso em um estudo recente (Santos et al. 2017). A especificidade dos primers foi testada utilizando-se amostras de DNA extraído de sangue de bovinos infectados com cada um dos três patógenos alvos (A. marginale, B. bigemina ou B. bovis), com o mesmo kit comercial citado acima para as amostras de campo. Essas amostras de sangue pertenciam ao banco de sangue infectado por agentes da TPB, de um dos autores deste trabalho (M.F.B. Ribeiro). Em nenhum momento houve reação cruzada entre patógenos nos três diferentes protocolos de PCR, mostrando-se ser, portanto, 100\% específico. Com relação à sensibilidade, as amostras de controles positivos foram testadas e positivas na PCR até a diluição de $10^{-2}$, o que representava cerca de 2,5 $\mu$ g de DNA total extraído de sangue infectado.

0 produto amplificado na PCR foi visualizado em gel de Agarose a 1,5\% e corado com Brometo de Etídio. Foram consideradas positivas as amostras que geraram bandas visíveis de aproximadamente 300 pares de bases, correspondente ao mesmo padrão de migração da banda gerado pelo controle positivo correspondente.

Os produtos de PCR de algumas amostras positivas na PCR foram purificados com o uso de Exosap ${ }^{\circledR}$ (USB) conforme recomendações do fabricante e submetidos ao sequenciamento de nucleotídeos em sequenciador automático de DNA (Applied Biosystems/Thermo Fisher Scientific, model ABI 3500 Genetic Analyzer, Foster City, California, USA), conforme instruções do fabricante. As sequências obtidas foram submetidas ao programa "BLAST analysis" (Altschul et al. 1990) para determinar similaridades com outras sequências disponíveis.

Infestação por carrapatos Rhipicephalus (Boophilus) microplus. Foram selecionadas aleatoriamente 10 vacas de cada propriedade para contagem e coleta de carrapatos. A contagem de $R$. (B.) microplus (fêmeas $>4,5 \mathrm{~mm}$ ) foi realizada em um dos lados do animal, incluindo virilha, úbere e axila, sendo o resultado multiplicado por dois para obtenção dos níveis de infestação por animal. Os bezerros também foram inspecionados quanto ao parasitismo por carrapatos. As coletas foram exclusivamente de fêmeas ingurgitadas, as quais foram colocadas em estufa climatizada $\left(25^{\circ} \mathrm{C}, 80 \%\right.$ relative humidity, escotophase) do tipo B.O.D. (Biochemical Oxygen Demand) durante oito dias, para posterior avaliação da hemolinfa através da coloração de Giemsa, conforme previamente descrito (Quintão-Silva et al. 2007). Os carrapatos que apresentaram hemolinfa positiva para Babesia sp. foram armazenados em microtubos e mantidos congelados a $-20^{\circ} \mathrm{C}$ para realização da extração de DNA e PCR para Babesia spp. conforme descrito acima.
Variação sazonal de dípteros. Em cada uma de três fazendas (propriedades A, D e E) foram colocadas uma armadilha NZI e uma armadilha CANNOPY para coletas de dípteros hematófagos, conforme previamente descrito (Barros et al. 2003). As armadilhas foram montadas uma vez ao mês durante oito dias, e a cada dois dias os coletores foram substituídos e o material coletado armazenado a seco, em recipientes contendo naftalina, para posterior identificação taxonômica seguindo literatura vigente (Krolow et al. 2007, Turcatel et al. 2007). Por motivos logísticos, não foi possível a coleta sistemática de dípteros nas propriedades B e C.

Dados climáticos. Durante os meses do experimento foram coletados os dados climáticos de umidade relativa do ar, temperatura e índices pluviométricos para cada local ou mesorregião amostrada. Os dados foram obtidos através do Instituto Nacional de Metereologia (INMET), da Empresa de Assistência Técnica e Extensão Rural (EMATER-Patos) e da Agência Executiva de Gestão das Águas do Estado da Paraíba (AESA).

Análises estatísticas. Os valores de hematócrito dos bezerros foram comparados com os resultados de PCR através do teste $t$ de Student, com o intuito de verificar se as amostras positivas na PCR para A. marginale, B. bigemina ou B. bovis apresentavam menores valores de hematócrito, quando comparadas com as amostras negativas. As análises foram realizadas através do programa Minitab 16. Os resultados foram considerados estatisticamente significantes se $P<0,05$.

\section{RESULTADOS}

\section{PCR dos bezerros}

Dos 41 bezerros monitorados durante o primeiro ano de vida, 25 (61,0\%) apresentaram PCR positivo para Anaplasma marginale, 7 (17,1\%) para Babesia bigemina e $3(7,3 \%)$ para B. bovis. Casos de positividade na PCR apenas por $A$. marginale foram observados em 18 bezerros, positividade mista por A. marginale e B. Bigemina ocorreram em 4 animais, positividade tripla foi detectada em 3 animais. Dezesseis (39,0\%) animais não apresentaram positividade na PCR para nenhum dos agentes estudados.

Os valores de incidência da infecção por $A$. marginale variaram de 83,3\% a 100\% em quatro fazendas (Quadro 1) sendo que em 84,0\% (21/25) dos bezerros a infecção ocorreu nos primeiros quatro meses de vida. Na fazenda A os 14 bezerros acompanhados no experimento permaneceram negativos para $A$. marginale.

Quanto a B. bigemina, a infecção ocorreu apenas em duas propriedades (D e E) com incidências de 12,5\% e 85,7\%, respectivamente (Quadro 1). Na propriedade D, dos sete bezerros monitorados, apenas um se infectou no oitavo mês de vida. Na propriedade E, seis dos sete bezerros monitorados infectaram-se precocemente, entre o primeiro e quinto mês de vida. A infecção por B. bovis foi observada somente na propriedade E, com percentual de incidência de 42,8\%. Os animais da propriedade $\mathrm{E}$ foram infectados pelos três agentes da TPB, enquanto a propriedade A não apresentou bezerros infectados por nenhum dos agentes.

Os resultados dos sequenciamentos de DNA realizados nos produtos amplificados por PCR de amostras dos bezerros estão apresentados nos Quadros 2-4. As sequências das amostras de $A$. marginale identificadas nas propriedades B, C, D e E corresponderam a quatro genótipos distintos, sendo que o mais frequente apresentou alta similaridade 
Quadro 1. Incidência da infecção por Anaplasma marginale, Babesia bigemina e Babesia bovis em bezerros bovinos durante o primeiro ano de vida em cinco fazendas da Paraíba, dentro do período de julho/2010 a janeiro/2012

\begin{tabular}{|c|c|c|c|c|c|c|c|}
\hline \multirow{2}{*}{ Fazenda } & \multirow{2}{*}{$\begin{array}{c}\mathrm{N}^{\circ} \text { de bezerros } \\
\text { amostrados de } 14 / 14 \\
\text { dias durante o primeiro } \\
\text { ano de vida }\end{array}$} & \multicolumn{6}{|c|}{$\begin{array}{l}\text { Número de bezerros positivos que se infectaram, segundo a idade (em meses) da primeira detecção por } \\
\text { PCR e valor da incidência (\%) durante o primeiro ano de vida }\end{array}$} \\
\hline & & № bezerros & $\%$ & № bezerros & $\%$ & № bezerros & $\%$ \\
\hline B & 6 & $5(1,1,1,1,1)$ & 83,3 & 0 & 0 & 0 & 0 \\
\hline $\mathrm{C}$ & 7 & $6(1,2,2,3,3,4)$ & 85,7 & 0 & 0 & 0 & 0 \\
\hline Total & 41 & 25 (1 a 8) & 61,0 & 7 (1 a 8) & 17,1 & $3(3$ a 7$)$ & 7,3 \\
\hline
\end{tabular}

Quadro 2. Resultados de análise de similaridade (Blast analysis) das sequências de DNA de produtos de PCR com primers direcionados a um fragmento de 340-pb do gene rap-1 de Babesia bigemina, em amostras de sangue de bezerros de fazendas da Paraíba

\begin{tabular}{|c|c|c|c|c|c|}
\hline \multirow{2}{*}{ Bezerro } & \multirow{2}{*}{ Origem da amostra } & \multicolumn{4}{|c|}{ Maior similaridade no Genbank (BLAST analysis) } \\
\hline & & Número de acesso* & $\%$ & Origem & Cepa \\
\hline 2 & Fazenda D & AY146980 & 100 & Argentina & S1A \\
\hline 2 & Fazenda E & AY146980 & 100 & Argentina & S1A \\
\hline 4 & Fazenda E & AY146980 & 100 & Argentina & S1A \\
\hline 5 & Fazenda E & AY146980 & 100 & Argentina & S1A \\
\hline
\end{tabular}

* Em todos os casos, as sequências geradas neste estudo tiveram $100 \%$ de cobertura (query cover) pelas sequências correspondentes a esse número de acesso.

Quadro 3. Resultados de análise de similaridade (Blast analysis) das sequências de DNA de produtos de PCR com primers direcionados a um fragmento de 347-pb do gene rap-1 de Babesia bovis, em amostras de sangue de bezerros de fazendas da Paraíba

\begin{tabular}{|c|c|c|c|c|c|}
\hline \multirow{2}{*}{ Bezerro } & \multirow{2}{*}{ Origem da amostra } & \multicolumn{4}{|c|}{ Maior similaridade no Genbank (BLAST analysis) } \\
\hline & & Numero de acesso* & $\%$ & Origem & Cepa \\
\hline 4 & Fazenda E & FJ588012 & 100 & Brasil & Sudeste \\
\hline 5 & Fazenda E & FJ588010 & 100 & Brasil & Nordeste \\
\hline 6 & Fazenda E & FJ588010 & 100 & Brasil & Nordeste \\
\hline
\end{tabular}

* Em todos os casos, as sequências geradas neste estudo tiveram $100 \%$ de cobertura (query cover) pelas sequencias correspondentes a esses números de acesso.

Quadro 4. Resultados de análise de similaridade (Blast analysis) das sequências de DNA de produtos de PCR com primers direcionados a um fragmento de 300-pb do gene msp1a de Anaplasma marginale, em amostras de sangue de bezerros de fazendas da Paraíba

\begin{tabular}{|c|c|c|c|c|c|}
\hline \multirow{2}{*}{ Bezerro } & \multirow{2}{*}{ Origem da amostra } & \multicolumn{4}{|c|}{ Maior similaridade no Genbank (BLAST analysis) } \\
\hline & & Numero de acesso* & $\%$ & Origem & Cepa \\
\hline 1 & Fazenda C & JN885133 & 99 & Brasil & I15 (M. gouazoubira) \\
\hline 2 & Fazenda C & JN885133 & 99 & Brasil & I15 (M. gouazoubira) \\
\hline 7 & Fazenda C & JN885133 & 99 & Brasil & I15 (M. gouazoubira) \\
\hline 5 & Fazenda D & FJ195757 & 98 & Taiwan & TWN6 \\
\hline 3 & Fazenda E & FJ195757 & 98 & Taiwan & TWN6 \\
\hline 4 & Fazenda E & AY846868 & 98 & Israel & Israeli Lhavot-Habasan \\
\hline 5 & Fazenda B & FJ195757 & 99 & Taiwan & TWN6 \\
\hline 6 & Fazenda B & FJ195757 & 99 & Taiwan & TWN6 \\
\hline 7 & Fazenda D & JN885132 & 99 & Brasil & I19 (M. gouazoubira) \\
\hline 7 & Fazenda E & JN885131 & 100 & Brasil & I10 (M. gouazoubira) \\
\hline
\end{tabular}

*Em todos os casos, as sequências geradas neste estudo tiveram $100 \%$ de cobertura (query cover) pelas sequencias correspondentes a esses números de acesso. 
com amostras encontradas em Mazama gouazoubira (veado catingueiro) descritas no Brasil. As sequências de B. bigemina das propriedades $\mathrm{D}$ e $\mathrm{E}$ corresponderam a um único genótipo com $100 \%$ de similaridade com amostra descrita na Argentina. Já as sequências de B. bovis corresponderam a dois genótipos com $100 \%$ de similaridade com duas amostras descritas no Brasil.

\section{Carrapatos Rhipicephalus (Boophilus) microplus}

A presença de carrapatos $R$. (B.) microplus foi verificada somente nas propriedades D e E, sendo que as contagens variaram de 4 a 132 fêmeas por animal. Nos bezerros a variação na contagem foi de 2 a 66 carrapatos. Os animais apresentaram infestações com intensidade irregular durante 0 ano, com aumento no período de chuva (dados não mostrados).

Durante o estudo, foram coletadas 46 fêmeas ingurgitadas de $R$. (B.) microplus dos bovinos. Após serem incubadas em estufa, em apenas duas fêmeas ingurgitadas, colhidas de bovinos na propriedade E, foram encontradas formas de esporocinetos compatíveis com Babesia sp, através do exame de hemolinfa corado com Giemsa. Esses dois carrapatos foram submetidos aos mesmos protocolos de PCR citados acima, resultando em positividade apenas para a PCR para B. bigemina. Os produtos de PCR foram sequenciados, resultando em sequências $100 \%$ às identificadas em bezerros da propriedade E (Quadro 2).

\section{Variação sazonal de dípteros}

Foram capturados 930 tabanídeos nas propriedades A, D e E, sendo a distribuição mensal apresentada na Figura 1. 0 total de tabanídeos das propriedades A e E foram agrupados, por representarem a mesma mesoregião (Sertão). Os valores para a propriedade D foram apresentados separadamente, por representarem outra mesorregião (Cariri). No total, foram identificados os seguintes taxa com suas respectivas quantidades e frequências: Tabanus claripennis (658 espécimes; $70,7 \%$ do total de tabanídeos), Tabanus sp. (130; 14,0\%), Lepiselaga crassipes $(112 ; 12,0 \%)$, Tabanus occidentalis (9; 1,0\%), Dichelacera sp. (7; 0,7\%), Lepiselaga sp. (4; 0,4\%), Chlorotabanus sp. (4; 0,4\%), Chrysops sp. (3; 0,3), Stenotabanus sp. (2; $0,2 \%)$ e Poeciloderas sp. $(1 ; 0,1 \%)$. A maioria dos taxa acima foi encontrada nas três propriedades; as únicas exceções foram a exclusividade de Poeciloderas sp. na propriedade D, associada às ausências de T. occidentalis, Dichelacera sp., Chrysops sp. e Stenotabanus sp. na propriedade D, e as ausências de Dichelacera sp., Lepiselaga sp. e Stenotabanus sp. na propriedade E.
Picos populacionais de tabanídeos ocorreram em abril, julho e novembro/2010 e fevereiro, julho-agosto e novembro/2011 em São José de Espinharas/Piancó (Sertão). Em Cabaceiras (Cariri), foi observado um pico bem definido em fevereiro/2011, os demais (novembro/2010 e maio/2011) foram menos evidentes e não se repetiram no ano seguinte (Fig.1). De modo geral, as épocas de maior abundância destes vetores estiveram diretamente associadas à estação chuvosa ou à ocorrência de chuvas nos meses anteriores ao pico em cada região (Fig.2). Durante o mesmo período, também foram capturados um total de 684 moscas-dos-estábulos (Stomoxys calcitrans), porém cerca de $90 \%$ delas foram capturadas entre março e julho de 2010 apenas na propriedade A.

\section{Hematócrito dos bezerros}

Os valores médios, desvio padrão e amplitude de hematócrito dos bezerros positivos e negativos na PCR para A. marginale, $B$. bigemina e $B$. bovis estão apresentados no Quadro 5. As amostras positivas na PCR, tanto para A. marginale como para $B$. bigemina, apresentaram valores de hematócrito significativamente menores que as amostras negativas na PCR. No caso de $B$. bovis, as médias do hematócrito foram estatisticamente similares $(\mathrm{P}=0,07)$ entre as amostras positivas e negativas na PCR.

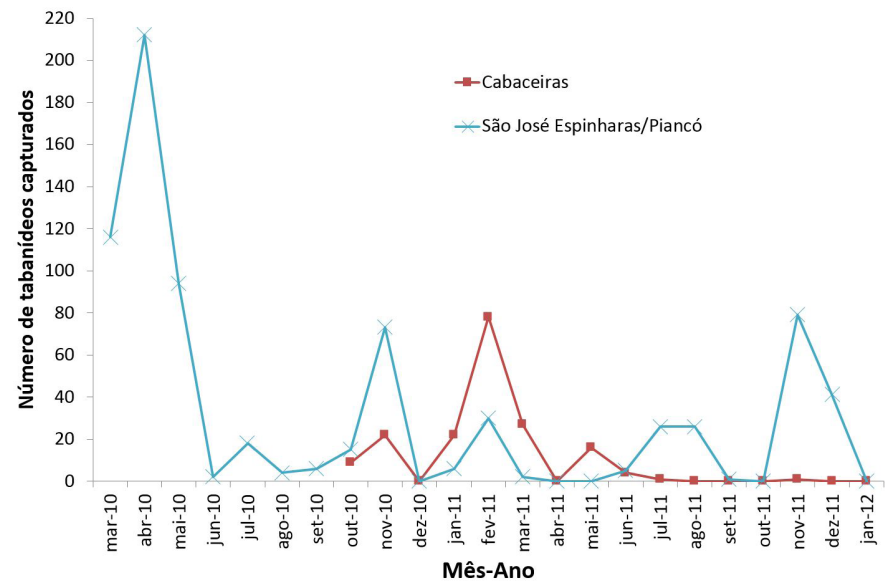

Fig.1. Número total de tabanídeos adultos capturados por armadilhas Canopy e NZI, armadas por um período de oito dias consecutivos em cada mês, nas Fazendas A e B (São José de Espinharas/Piancó) e D (Cabaceiras), Paraíba, de março/2010 a janeiro/2012.

Quadro 5. Avaliação comparativa dos valores de hematócrito das amostras de sangue de bezerros, positivas (+) e negativas (-) na PCR para Anaplasma marginale, Babesia bigemina e Babesia bovis, em propriedades rurais do semi-árido paraibano, de 2010 a 2012

\begin{tabular}{|c|c|c|c|c|c|c|}
\hline \multirow{2}{*}{ Hematócrito } & \multicolumn{2}{|c|}{ A. marginale (4 fazendas) } & \multicolumn{2}{|c|}{ B. bigemina (2 fazendas) } & \multicolumn{2}{|c|}{ B. bovis (1 fazenda) } \\
\hline & $\mathrm{PCR}+(78)^{*}$ & PCR- $(84)^{*}$ & $\mathrm{PCR}+(21)^{*}$ & PCR- $(114)^{*}$ & $\mathrm{PCR}+(12)^{*}$ & PCR- $(73)^{*}$ \\
\hline Média $^{+}$ & $28,5^{\mathrm{a}}$ & $35,5^{b}$ & $23,9^{\mathrm{a}}$ & $31,7^{\mathrm{b}}$ & $23,2^{\mathrm{a}}$ & $24,8^{\mathrm{a}}$ \\
\hline Desvio padrão & 7,2 & 5,8 & 4,7 & 4,4 & 2,2 & 4,3 \\
\hline
\end{tabular}

* Número de amostras de sangue incluídas na análise, considerando-se somente as fazendas em que houve pelo menos um animal que se infectou pelo patógeno em questão; ${ }^{\mathrm{a}, \mathrm{b}}$ Letras sobrescritas diferentes indicam que as médias de hematócrito entre amostras positivas e negativas na PCR foram estatisticamente diferentes $(P<0.05)$, considerando cada patógeno separadamente. 


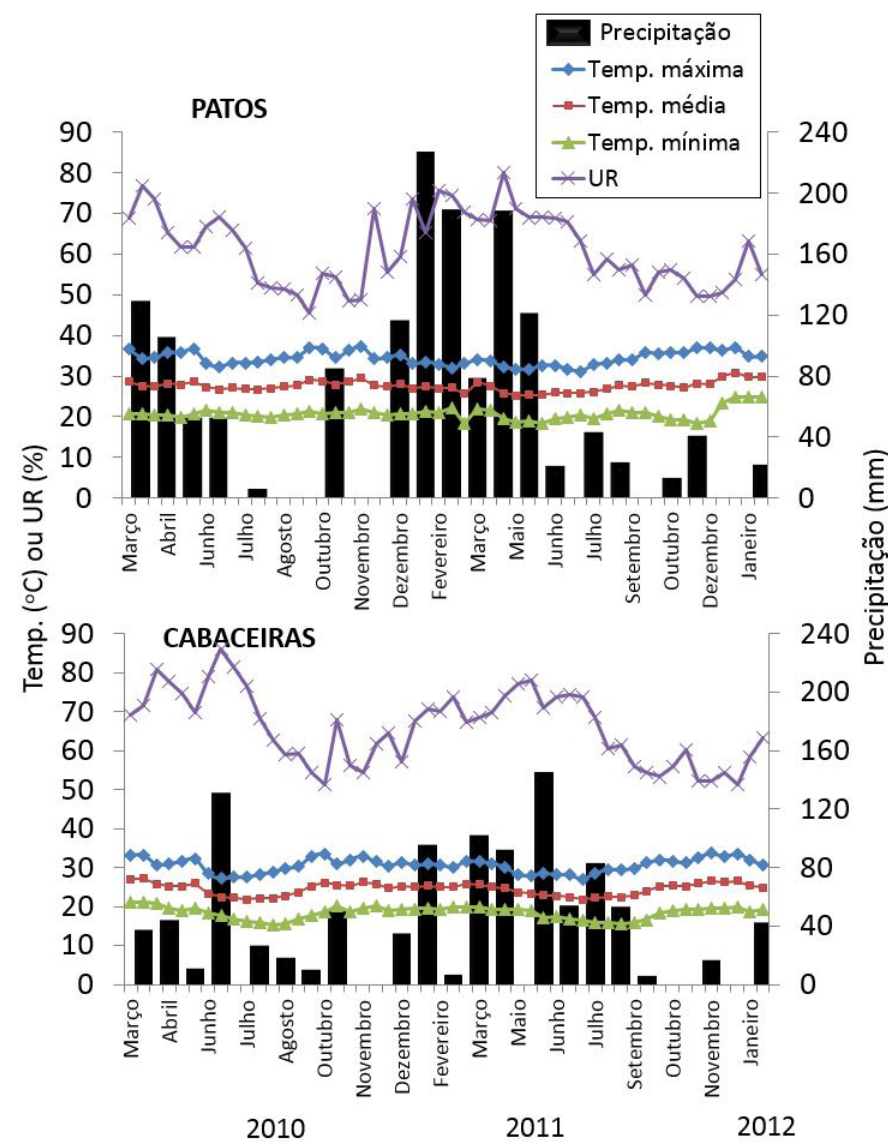

Fig.2. Valores médios de temperatura (temp.) máxima, média e mínima, umidade relativa (UR) e valor total mensal de chuvas (precipitação) registrados para os Municípios de Patos e Cabaceira, Paraíba, de março/2010 a janeiro/2012.

\section{DISCUSSÃO}

No Brasil, a transmissão de Babesia bigemina e Babesia bovis aos bovinos está restrita à presença do carrapato Rhipicephalus (Boophilus) microplus, vetor biológico desses patógenos (Alonso et al. 1992). O risco de um bezerro infectar-se com Babesia sp. numa determinada região fisiográfica está relacionado a diversos fatores, tais como: a probabilidade de ser infestado por carrapatos infectados; número de picadas de carrapatos que os animais recebem diariamente e proporção da infecção por Babesia spp. nas larvas de R. (B.) microplus (Mahoney \& Ross 1972). Por sua vez, o risco de carrapatos infectarem-se com Babesia sp. está relacionado com a prevalência da infecção no rebanho bovino. Através de modelos matemáticos, Smith (1983) encontrou que a manutenção de 10 a 40 teleóginas de $R$. (B.) microplus por animal/dia corresponderia a um nível de infestação adequado para manter um nível adequado de proteção de rebanhos Bos taurus contra quadros clínicos por Babesia spp., gerando uma estabilidade enzoótica, sem, contudo, acarretar prejuízos econômicos significativos ao sistema de produção.

Durante o estudo, a presença de animais infestados por $R$. (B.) microplus foi observada somente em duas propriedades (D e E). Mesmo nestas propriedades as infestações foram baixas e de forma irregular nos diferentes meses do ano. Este fato provocou o estabelecimento de instabilidade enzoótica para ambas as espécies de Babesia na propriedade $D$, sendo que na propriedade $E$ foi suficiente para a instalação da estabilidade para B. bigemina. A ausência ou ocorrência de baixa infestação do vetor biológico justifica a ocorrência de instabilidade enzootica para Babesia spp. na maioria das propriedades localizadas no bioma da Caatinga Paraibana, conforme constatado em trabalhos recentes (Costa et al. 2011, 2013).

Nas duas propriedades onde ocorreu infecção de Babesia neste estudo, a incidência de B. bigemina foi maior do que a de B. bovis. Estudos têm mostrado que, em condições naturais, as frequências de infecção por Babesia spp. em larvas não alimentadas de $R$. microplus são baixas, sendo $0,04 \%$ para $B$. bovis e $0,23 \%$ para B. bigemina . Essa maior porcentagem de infecção por $B$. bigemina garantiria uma maior taxa de inoculação nos animais, resultando numa maior incidência desta espécie, quando comparada com B. bovis (Mahoney \& Mirre 1971, Mahoney \& Ross 1972, Quintão-Silva et al. 2007).

Apenas um genótipo de $B$. bigemina foi encontrado nas amostras sequenciadas de bovinos e de carrapatos das propriedades D e E, indicando ser o mesmo genótipo descrito na Argentina (Suarez et al. 2003). É possível que este genótipo esteja disseminado na América do Sul. As sequências de B. bovis foram representadas por dois genótipos, um inicialmente descrito no Sudeste (estado de São Paulo) e outro no Nordeste (estado da Bahia) (Ramos et al. 2012). Essa diversidade de genótipos encontrada no presente estudo deve ser considerada em futuros estudos de controle da TPB no sertão da Paraíba por meio de vacinas, uma vez a resposta imune protetora pode variar conforme a heterogeneidade da amostra de antígeno usada (Ramos et al. 2012).

Os valores de incidência da infecção por Anaplasma marginale indicam uma estabilidade enzoótica nas propriedades B, C, D e E, onde mais de $80 \%$ dos bezerros se infectaram antes de seis meses de idade. A ausência de infestações pelo carrapato $R$. (B.) microplus nas propriedades B e C durante o estudo reforça a importância de outras formas de transmissão de A. marginale entre bovinos no semiárido paraibano. Uma delas seria a transmissão mecânica, principalmente através de tabanídeos, conforme já demonstrado experimentalmente (Hawkins et al. 1982). 0 fato de vários bezerros já estarem infectados por A. marginale desde a primeira amostra de sangue colhida no primeiro mês de vida neste estudo poderia estar relacionado com os maiores picos populacionais de tabanídeos observados no início do estudo (Fig.1). Por outro lado, esta infecção precoce poderia estar relacionada à transmissão congênita do agente, já comprovada para A. marginale em bovinos (Benesi et al. 1999, Silvestre et al. 2016). Por fim, não se pode descartar a transmissão iatrogênica, que não foi avaliada no presente estudo.

Este constitui o primeiro trabalho brasileiro onde foi realizada a identificação das espécies de tabanídeos que podem estar envolvidas na transmissão de $A$. marginale. Ressalta-se o predomínio da espécie Tabanus claripennis, ocorrendo principalmente nos períodos de chuva. Hawkins et al. (1982) verificaram que os tabanídeos são eficientes transmissores de A. marginale, bastando 10 picadas para transmitir a infecção de um bovino na fase aguda para o animal susceptível. A riquetsia permanece viável nas peças bucais até duas horas apos o 
repasto sanguíneo, facilitando a transmissão. Os tabanídeos são importantes vetores mecânicos por provocarem intensa reação no hospedeiro causando interrupção frequente do repasto sanguíneo, além de necessitar do repasto para o desenvolvimento dos ovos (Barros et al. 2003).

Trabalhos têm demonstrado, tanto no Brasil como nos Estados Unidos, que algumas amostras de A. marginale são transmitidas por carrapatos, enquanto outras são por via mecânica principalmente por moscas hematófagas (Wickwire et al. 1987, Gonçalves Ruiz et al. 2005). As análises de sequenciamento de DNA de produtos amplificados por PCR mostraram que pelo menos três genótipos distintos de A. marginale circulam entre os bovinos do semiárido paraibano. Esses resultados corroboram o conceito de heterogenicidade genética de amostras de $A$. marginale descrita em diferentes países (Fuente et al. 2007). É possível que esta variabilidade de genótipos esteja relacionada com diferentes formas de transmissão, quer a biológica via carrapato ou a mecânica principalmente por moscas hematófagas. Outro fato que chama atenção é que as amostras de $A$. marginale detectadas na Caatinga apresentam alta similaridade com amostras descritas em cervídeos, sobretudo Mazama gouazoubira (Silveira et al. 2012). Como as criações de bovinos nas propriedades estudadas são do tipo extensivo podemos teorizar que a transmissão da anaplasmose no semiárido paraibano ocorre principalmente por tabanídeos e que os animais silvestres poderiam ter alguma importância como reservatórios da riquetsia. Muito embora a área do estudo esteja dentro da distribuição geográfica do cervídeo Mazama gouazoubira no Brasil (Black-Décima et al. 2010), a presença deste animal nas propriedades estudadas não pode ser confirmada com exatidão no presente estudo.

Neste estudo, nenhum dos 14 bezerros da propriedade A se infectou no primeiro ano de vida, indicando um cenário específico de instabilidade enzoótica nesta propriedade. Neste local não foi verificado a presença de $R$. (B.) microplus. Em um trabalho anterior realizado neste mesma propriedade (Costa et al. 2013), todas as 24 vacas amostradas foram sorologicamente negativas para A. marginale e Babesia spp. (M.B. Labruna, comunicação pessoal). Desta forma, mesmo com a presença de tabanídeos na área, a incidência zero de A. marginale nos bezerros se justifica pela possível ausência de animais portadores (ex. vacas infectadas). Esta situação demonstra que no semiárido, mesmo em condições de criação extensiva, podem ocorrer áreas livres da infecção. Animais provenientes destas propriedades devem merecer atenção ao serem comercializadas por correr alto risco de sofrerem infecção aguda com alta taxa de letalidade.

Os resultados de PCR deste estudo foram estatisticamente corroborados pelas dosagens de hematócritos dos bezerros, uma vez que houve associação significativa entre PCR positivo para A. marginale ou B. bigemina e menores valores de hematócrito. Tal associação se deve à patogenia da doença causada por esses dois agentes, que se caracteriza fundamentalmente por diminuição expressiva do número de eritrócitos (Bock et al. 2004, Facury-Filho et al. 2012). Por outro lado, esta diminuição é menos expressiva na doença causada por B. bovis (Bock et al. 2004), justificando a ausência de associação significativa entre PCR positivo para este agente e menores valores de hematócrito (Quadro 5).

\section{CONCLUSÕES}

0 presente estudo demonstra que, mesmo avaliando apenas cinco propriedades rurais, a incidência dos agentes da tristeza parasitária bovina (TPB) ocorreu de forma heterogênea na região, corroborando o status de área de instabilidade enzoótica para TPB previamente relatado para o semiárido paraibano.

A vacinação de bezerros no primeiro ano de vida parece ser a alternativa mais viável para evitar surtos de TPB nas propriedades da região, assim como é empregada em outras áreas de instabilidade enzoótica do sul da América do Sul, áreas marginais da distribuição geográfica de Rhipicephalus (Boophilus) microplus.

Agradecimentos.- Este trabalho foi financiado pela Fundação de Amparo à Pesquisa do Estado de São Paulo (FAPESP processo 2009/53193-5), Conselho Nacional de Desenvolvimento Científico e Tecnológico (CNPq processo 552389/2009-9) e Coordenação de Aperfeiçoamento de Pessoal de Nível Superior (CAPES/PROEX 2327/2015).

\section{REFERÊNCIAS}

Alonso M., Arellano-Sota C., Cereser V.H., Cordoves C.O., Guglielmone A.A. Kessler R., Mangold A.J., Nari A., Patarroyo J.H., Solari M.A., Veja C.A., Vizcaino 0. \& Camus C.A. 1992. Epidemiology of bovine anaplasmosis and babesiosis in Latin America and the Caribbean. Rev. Scient. Tech. Off. Int. Epizoot., Paris, 11:713-733.

Altschul S.F., Gish W., Miller W., Myers E.W. \& Lipman D.J. 1990. Basic local alignment search tool. J. Mol. Biol. 215(3):403-410. http://dx.doi. org/10.1016/S0022-2836(05)80360-2. PMid:2231712.

Andrade-Lima D. 1981. The Caatinga dominium. Revta Bras. Bot. 4:149-153

Barros A.T.M., Foil L.D. \& Vazquez S.A.S. 2003. Mutucas (Diptera: Tabanidae) do Pantanal: Abundância Relativa e Sazonalidade na Sub-Região da Nhecolândia. Bolm Pesquisa 48, Embrapa Pantanal, Corumbá/MS, p.1-18

Benesi F.J., Howard D.L., Sá C.S.C. \& Birgel Junior E.H. 1999. Relato de um caso de transmissão transplacentária de anaplasmose bovina: observações clínico-laboratoriais. Revta Bras. Ciênc. Vet., Heredia, 6(3):175-176.

Black-Décima P., Rossi R.V., Vogliotti A., Cartes J.L., Maffei L., Duarte J.M.B., González S. \& Juliá J.P. 2010. Brown brocket deer Mazama gouazoubira (Fischer, 1814), p.190-201. In: Duarte J.M.B.\& González S. (Eds), Neotropical Cervidology: Biology and Medicine of Latin American Deer. Funep, Jaboticabal, Brazil; IUCN, Gland, Suiça.

Bock R., Jackson L., De Vos A. \& Jorgensen W. 2004. Babesiosis of cattle. Parasitology 129(Suppl.7):S247-S269. http://dx.doi.org/10.1017/ S0031182004005190. PMid:15938514.

Brown W.C., Norimine J., Knowles D.P. \& Goff W.L. 2006. Immune control of Babesia bovis infection. Vet. Parasitol. 138(1/2):75-87. http://dx.doi. org/10.1016/j.vetpar.2006.01.041. PMid:16510249.

Costa V.M.M., Ribeiro M.F.B., Duarte A.L.L., Mangueira J.M., Pessoa A.F.A., Azevedo S.S., Barros A.T.M., Riet-Correa F. \& Labruna M.B. 2013. Seroprevalence and risk factors for cattle anaplasmosis, babesiosis, and trypanosomosis in a Brazilian semiarid region. Revta Bras. Parasitol. Vet. 22(2):207-213. http://dx.doi.org/10.1590/S1984-29612013005000022. PMid:23802235

Costa V.M.M., Rodrigues A.L., Medeiros J.M.A., Labruna M.B., Simões S.V.D \& Riet-Correa F. 2011. Tristeza parasitária bovina no Sertão da Paraíba Pesq. Vet. Bras. 31(3):239-243. http://dx.doi.org/10.1590/S0100736X2011000300009.

Facury-Filho E.J., Carvalho A.Ú., Ferreira P.M., Moura M.F., Apolinário B.C., Santos L.P. \& Ribeiro M.F. 2012. Effectiveness of enrofloxacin for the treatment of experimentally-induced bovine anaplasmosis. Revta Bras. Parasitol. Vet. 21(1):32-36. http://dx.doi.org/10.1590/S1984-29612012000100007. PMid:22534942. 
Fuente J., Ruybal P., Mtshali M.S., Naranjo V., Shuqing L., Mangold A.J., Rodríguez S.D., Jiménez R., Vicente J., Moretta R., Torina A., Almazán C., Mbati P.M., Echaide S.T., Farber M., Rosario-Cruz R., Gortazar C. \& Kocan K.M. 2007. Analysis of world strains of Anaplasma marginale using major surface protein 1a repeat sequences. Vet. Microbiol. 119(2/4):382-390. http:// dx.doi.org/10.1016/j.vetmic.2006.09.015. PMid:17084044.

Guglielmone A.A. 1995. Epidemiology of babesiosis and anaplasmosis in South and Central America. Vet. Parasitol. 57(1/3):109-119. http://dx.doi. org/10.1016/0304-4017(94)03115-D. PMid:7597777.

Hawkins J.A., Love J.N. \& Hidalgo R.J. 1982. Mechanical transmission of anaplasmosis by tabanids (Diptera: Tabanidae). Am. J. Vet. Res. 43(4):732734. PMid:7073099.

James M.A., Coronado A., Lopez W., Melendez R. \& Ristic M. 1985. Seroepidemiology of bovine anaplasmosis and babesiosis in Venezuela. Trop. Anim. Health Prod. 17(1):9-18. http://dx.doi.org/10.1007/BF02356127. PMid:3887703.

Krolow T.K., Krüger R.F. \& Ribeiro P.B. 2007. Chave pictórica para os gêneros de Tabanidae (Insecta: Diptera) do bioma Campos Sulinos, Rio Grande do Sul, Brasil. Biota Neotrop. 7(2):253-264. http://dx.doi.org/10.1590/ S1676-06032007000200028.

Magonigle R.A. \& Newby T.J. 1984. Response of cattle upon exposure to Anaplasma marginale after elimination of chronic carrier infections. Am. J. Vet. Res. 45(4):695-697. PMid:6731981.

Mahoney D.F. \& Mirre G.B. 1971. Bovine babesiasis: estimation of infection rates in the tick vector Boophilus microplus (Canestrini). Ann. Trop. Med. Parasitol. 65(3):309-317. http://dx.doi.org/10.1080/00034983.1971.1 1686759. PMid:4999518.

Mahoney D.F. \& Ross D.R. 1972. Epizootiological factors in the control of bovine babesiosis. Aust. Vet. J. 48(5):292-298. http://dx.doi. org/10.1111/j.1751-0813.1972.tb05160.x. PMid:4672119.

Quintão-Silva M.G., Melo M.N. \& Ribeiro M.F.B. 2007. Comparison of duplex PCR and microscopic techniques for identification of Babesia bigemina and Babesia bovis in engorged females ticks of Boophilus microplus. Zoonoses Public Health 54(3/4):147-151. http://dx.doi.org/10.1111/j.18632378.2007.01037.x. PMid:17456146.

Ramos C.A.N., Araújo F.R., Alves L.C., Souza I.I.F., Guedes Junior D.S. \& Soares C.O. 2012. Genetic conservation of potentially immunogenic proteins among Brazilian isolates of Babesia bovis. Vet. Parasitol. 187(3/4):548552. http://dx.doi.org/10.1016/j.vetpar.2012.01.020. PMid:22309798.

Ruiz P.M., Passos L.M. \& Ribeiro M.F. 2005. Lack of infectivity of a Brazilian Anaplasma marginale isolate from Boophilus microplus ticks. Vet. Parasitol. 128(3/4):325-331. http://dx.doi.org/10.1016/j.vetpar.2004.11.017. PMid:15740870.

Sacco A.M.S. 2002. Controle de Surtos de Tristeza Parasitária Bovina. Circ. Téc. 26, Embrapa Pecuária Sul, Bagé. 4p.
Santos G.B., Gomes I.M., Silveira J.A.G., Pires L.C.S.R., Azevedo S.S., Antonelli A.C., Ribeiro M.F.B. \& Horta M.C. 2017. Tristeza parasitária em bovinos do semiárido pernambucano. Pesq. Vet. Bras. 37(1):1-7. http://dx.doi. org/10.1590/s0100-736x2017000100001.

Silva J.B., Gonçalves L.R., Varani A.M., André M.R. \& Machado R.Z. 2015. Genetic diversity and molecular phylogeny of Anaplasma marginale studied longitudinally under natural transmission conditions in Rio de Janeiro, Brazil. Ticks Tick Borne Dis. 6(4):499-507. http://dx.doi.org/10.1016/j. ttbdis.2015.04.002. PMid:25985719.

Silveira J.A., Rabelo E.M. \& Ribeiro M.F. 2012. Molecular detection of tickborne pathogens of the family Anaplasmataceae in Brazilian brown brocket deer (Mazama gouazoubira Fischer, 1814) and marsh deer (Blastocerus dichotomus Illiger, 1815). Transbound. Emerg. Dis. 59(4):353-360. http:// dx.doi.org/10.1111/j.1865-1682.2011.01278.x. PMid:22136597.

Silvestre B.T., Silveira J.A., Meneses R.M., Facury-Filho E.J., Carvalho A.U. \& Ribeiro M.F. 2016. Identification of a vertically transmitted strain from Anaplasma marginale (UFMG3): molecular and phylogenetic characterization, and evaluation of virulence. Ticks Tick Borne Dis. 7(1):80-84. http://dx.doi. org/10.1016/j.ttbdis.2015.09.001. PMid:26381444.

Smith R.D. 1983. Babesia bovis: computer simulation of the relationship between the tick vector, parasite, and bovine host. Exp. Parasitol. 56(1):2740. http://dx.doi.org/10.1016/0014-4894(83)90094-2. PMid:6873224.

Souza F.A.L. 2011. Babesiose e anaplasmose em rebanhos bovinos leiteiros do Estado do Piauí, Brasil. Dissertação de Mestrado, Universidade Federal do Piauí, Teresina. 74p.

Suarez C.E., Palmer G.H., Florin-Christensen M., Hines S.A., Hotzel I. \& McElwain T.F. 2003. Organization, transcription, and expression of rhoptry associated protein genes in the Babesia bigemina rap-1 locus. Mol. Biochem. Parasitol. 127(2):101-112. http://dx.doi.org/10.1016/S0166-6851(02)00311-0. PMid:12672519.

Trindade H.I. 2010. Soroprevalência de tristeza parasitária em bezerros na região de Araguaína, Estado de Tocantins, Brasil. Dissertação de Mestrado, Universidade Federal do Tocantins, Araguaína. 71p.

Turcatel M., Carvalho C.J.B. \& Rafael J.A. 2007. Mutucas (Diptera: Tabanidae) do estado do Paraná, Brasil: chave de identificação pictórica para subfamílias, tribos e gêneros. Biota Neotrop. 7(2):265-278. http://dx.doi.org/10.1590/ S1676-06032007000200029.

Wickwire K.B., Kocan K.M., Barron S.J., Ewing S.A., Smith R.D. \& Hair J.A. 1987. Infectivity of three Anaplasma marginale isolates for Dermacentor andersoni. Am. J. Vet. Res. 48(1):96-99. PMid:3826850.

Wright I.G. 1990. Immunodiagnosis and immunoprophylaxis against the haemoparasites Babesia sp. and Anaplasma sp. in domestic animals. Rev. Scient. Tech. Off. Int. Epizoot., Paris, 9(2):345-356. 